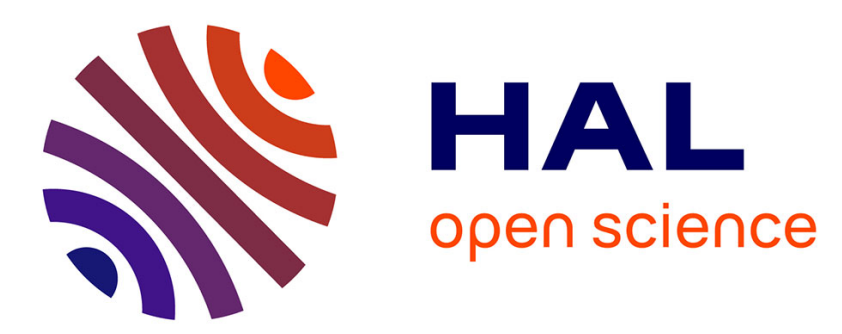

\title{
Irreversible investment, uncertainty, and ambiguity: The case of bioenergy sector
}

Pierre-André Jouvet, Elodie Le Cadre, Caroline Orset Orset

\section{To cite this version:}

Pierre-André Jouvet, Elodie Le Cadre, Caroline Orset Orset. Irreversible investment, uncertainty, and ambiguity: The case of bioenergy sector. Energy Economics, 2012, 34 (1), pp.45-53. 10.1016/j.eneco.2011.08.018 . hal-01500840

\section{HAL Id: hal-01500840 https://hal.science/hal-01500840}

Submitted on 18 Apr 2017

HAL is a multi-disciplinary open access archive for the deposit and dissemination of scientific research documents, whether they are published or not. The documents may come from teaching and research institutions in France or abroad, or from public or private research centers.
L'archive ouverte pluridisciplinaire HAL, est destinée au dépôt et à la diffusion de documents scientifiques de niveau recherche, publiés ou non, émanant des établissements d'enseignement et de recherche français ou étrangers, des laboratoires publics ou privés. 


\title{
Irreversible investment, uncertainty, and ambiguity: the case of bioenergy sector th
}

\author{
Pierre-André Jouvet ${ }^{\mathrm{a}, \mathrm{c}}$, Elodie Le Cadre ${ }^{\mathrm{a}, \mathrm{b}}$, Caroline Orset ${ }^{\mathrm{b}}$ \\ ${ }^{a}$ EconomiX-CNRS, Université Paris Ouest Nanterre La Défense. \\ ${ }^{b}$ UMR INRA-AgroParisTech Economie Publique \\ ${ }^{c}$ Climate Economics Chair
}

\begin{abstract}
We analyze production and investment decisions of an agent in industrial activities that are characterized by two forms of uncertainty: demand uncertainty (in terms of number of buyers) and competitive effect uncertainty (in terms of other energy resource). We apply our model on the bioenergy industries. We compare the case of an ambiguity neutral agent with that of an ambiguity averse agent. We show that the investment decision of an agent depends on the effects of both the capital investment and the level of production on the cost and the uncertainty the agent is confronted with. Moreover, we find that ambiguity aversion tends to decrease the agent's optimal levels of production and investment. Our numerical analysis of the French case illustrates the different effects associated with demand uncertainty and competitive effect uncertainty.
\end{abstract}

Keywords: Ambiguity, Bioenergy, Irreversible investment, Uncertainty. JEL Classification: D21, D81, Q42, Q23.

\footnotetext{
${ }^{\star}$ We would like to thank Meglena Jeleva, Alain Ayong Le Kama and two anonymous reviewers for their helpful comments and discussions. The views expressed in this article are the sole responsibility of the authors and do not necessarily reflect those of their institutions. The traditional disclaimer applies. Thanks to Sofiproteol for its fundings.

Email addresses: pjouvet@u-paris10.fr (Pierre-André Jouvet), elodie.lecadre@agroparistech.fr (Elodie Le Cadre), caroline.orset@agroparistech.fr (Caroline Orset)
} 


\section{Introduction}

Investments into renewable technologies will have to develop in order to reach the renewable energy target of $20 \%$ fixed by the European Union (EU) for 2020 1 1 To reach the future targets set out by the EU, significant amounts of biomass and investments into biomass based technologies will be necessary: ${ }^{2}$ Biomass is key to the development of renewable energies, but it must undergo a pretreatment and densification process before it can be transported and stored. Indeed, biomass is a resource that is heterogeneous in quality and is not homogeneously distributed across space. Therefore, the large range of biomass types is not directly usable in some feeding systems and conversion processes. Investment in new pre-treatment facilities is a necessary step in the total biomass supply chain in order to save transport, material, handling costs for users and to reduce investments in transformation facilities.

These pre-treatment processes are still in progress and the biomass market is emerging. Although a potential investor has information about the demand and the competitive effect on the supply market, this information still remains imperfect.

Indeed, due to the novelty of this market, the agent cannot get a perfect knowledge on the number of buyers before starting the production. He will either have to supply a few potential buyers such as heat and electricity producers, needing to replace coal, or a larger number of potential buyers including producers of second generation biofuel and heat and electricity producers. This uncertainty then affects the agent's perception of the average price. Here and hereafter, we define this uncertainty as the demand uncertainty.

Moreover, the competition effect from other energy resource on the price of pretreated biomass is also not well-known by the agent. In fact, the biomass may be sold either to heating or power units as a substitute for coal (the selling price could then be indexed with coal prices) or to Biomass to Liquid (BtL) units as a substitute for fossil fuel and prices could then be indexed with oil prices, which fluctuate even more sharply than coal prices. So, uncertainty about competition affects the agent's perception of the average price and mostly the variance price. We define this uncertainty as the competitive effect uncertainty.

Considering these two kinds of uncertainty and their impact on the selling price, a biomass agent has to decide how much capital investment and produced units he will make in biomass activities. Capital investment, also called in the literature the cost of entry, in bioenergy production represents a quasi-sunk cost due to the fact that biomass torrefaction is a specific, and relatively expensive, process. This naturally raises the issue of the effect of both types of uncertainty and of the irreversibility on the investment level and production.

Furthermore, in the energy market, the instability of the economy may lead the agent to have uncertainties about his evaluation of the variance of the output price. We use the term

\footnotetext{
${ }^{1}$ In 2007, the European Commission has fixed the renewable energy target in the EU's overall mix to $20 \%$ in the final energy consumption by 2020 regarding 1990 . To reach this goal, the member states have adopted the pack energy-climate and renewable energy (European Commission, 2009) in particular which defines the operational measures to develop 20\% of renewable energies by 2020 .

${ }^{2}$ Currently biomass delivers around $4 \%$ of the EU's primary energy (EEA, 2008).
} 
'ambiguity' to indicate situations in which the odds of an uncertain event are not precisely known. In other words, a situation in which there is an 'uncertainty about uncertainty' 3 An agent who has doubts about the odds is considered as an ambiguity-averse agent. So a question arises: how an ambiguity-averse agent behaves when he makes his decisions concerning investment and production?

To understand the impact of uncertainty on investment and production in biomass activities, we propose a two-period model in which there is incomplete information about the number of buyers and the competitive effect. Under these uncertainties, an agent has to choose his capital investment for the production of pre-treated biomass units at the following period. We study the cases of an ambiguity-neutral agent and of an ambiguity-averse agent. Following Klibanoff et al. (2005), we extend our work by presenting ambiguity as a second order prior probability distribution over the set of plausible distributions of the competitive effect. This approach allows us to analyze the impact of ambiguity on the investment and production choices.

The standard theory of irreversible investments or quasi sunk cost (Henry, 1974, Sutton, 1991) and options values suggests a negative relation between investment and uncertainty (Dixit \& Pindyck, 1994). Empirical studies also confirm this negative relation (Carruth et al., 2000; Bond et al. 2005; Fan \& Zhu, 2010). However, (Kulatilaka \& Perotti, 1998; Sarkar, 2000) point out that an increase in uncertainty could increase the probability of investing, and thereby has a positive impact on investment. Moreover, Mohn \& Misund (2009) argue that any positive impact on investment arising from the fact that greater uncertainty, under certain circumstances, increases the marginal profitability of capital. In all these papers the effect of price uncertainty has been analyzed as the effect of demand uncertainty on capacity choice (Trigeorgis, 1996; Dangl, 1999; Isik et al., 2003, Elder \& Serletis, 2009, 2010). Considering real options approach, Murto et al. (2004) are interested with in the timing of investment projects under demand uncertainty and oligopolistic competition. The important characteristic is that the output price is influenced by both exogenous uncertainty and new capacity investments. This paper is closed to our approach with demand uncertainty and competitive effect even if there is no real uncertainty on the competition. Murto (2006) introduces two types of uncertainty by combining effect of technological uncertainty and uncertainty in output price with real options approach. However, no work has been done on the two types of uncertainty (demand uncertainty and competitive effect uncertainty) that affect prices in different ways: the perception of the average and the variance of the price. Concerning ambiguity, we refer to the basic literature on ambiguity with (Ellsberg, 1961) and Fellner (1961, 1965), the empirical investigations by Slovic \& Tversky (1974) and the recent literature with (Klibanoff et al., 2005) and Gollier (2006) to indicate situations for which the odds of an uncertain event are not precisely known. Determining how an ambiguity-averse agent decides to invest and produce in emerging technologies is an important line of research in entrepreneurial decision-making in BtL.

Using an analytical approach and numerical analysis, we first note that whatever the

\footnotetext{
${ }^{3}$ For more details on ambiguity approach, see Camerer $(1999)$; Etner et al. $(2010)$.
} 
certainty or uncertainty context, the agent never invests or produces when he thinks that an increase in capital increases the cost of one more unit. Moreover, we show that the agent's capital investment decision depends on the effects of the amount of capital invested, of the level of production on the cost and on the uncertainty to which the agent is confronted. Then, we observe asymmetric effects of demand uncertainty and competitive effect uncertainty on the optimal amount of investment and optimal production. Finally, we find that ambiguity aversion tends to decrease the agent's level of capital investment and production.

The French biomass pre-treatment industry (torrefaction) is taken as an example, and the empirical results show that the model developed here can provide useful advice for pretreatment biomass investment programs.

The remainder of the paper is organized as follows. Section 2 consists of a description of the model. Section 3 analyzes and compares the optimal investment and production decisions of both an ambiguity neutral agent and an ambiguity averse agent. Section 4 presents a numerical analysis. Finally, section 5 concludes.

\section{Model description}

We consider a two period model with a risk-neutral agent. The agent faces two types of uncertainty: demand uncertainty, in terms of number of buyers, and a competitive effect uncertainty. Indeed, whereas the agent knows that he is competing on the market of fuel providers $\stackrel{4}{4}^{4}$.e. he is a price taker $5^{5}$ he only has a subjective perception of his potential customers and of the severity of the market competition. Both types of uncertainty affect prices in different ways: the demand uncertainty pertains to the perception of the price average while the competition effect uncertainty pertains to the average and mostly the price variance.

We define four possible states of the world: a Low number of buyers and a Weak competition effect $(L W)$, a High number of buyers and a Weak competition effect $(H W)$, a Low number of buyers and a Strong competition effect $(L S)$ and High number of buyer and a Strong competition effect $(H S)$. We propose to divide the agent's subjective probabilities on these states in two kinds of beliefs: first, the agent's subjective probabilities are $\psi$ on the low number of buyers, and $(1-\psi)$ on the high number of buyers; second, the agent's subjective probabilities are $\theta$ on the strong competition, and $(1-\theta)$ on the weak competition. In addition, we consider that the 'right' value of the probability associated with the competitive effect uncertainty $\theta$ may be unknown. In this case, $\theta$ is a random variable, and it is called $\tilde{\theta}$. The agent associates a probability distribution $F(\theta)$ on $[\underline{\theta}, \bar{\theta}]$ which measures the subjective relevance of a particular $\theta$ probability. The competitive effect is then ambiguous in the sense that his beliefs depend on a probability distribution. Instability in the energy market can cause the agent to become uncertain about the true value of probability $\theta$, which pertains to

\footnotetext{
${ }^{4}$ Indeed, the agent knows that there already exists substitute of pre-treatment process which could provide the biomass consumers.

${ }^{5}$ The energy price is determined by the total supply of energy and each unit considers the price as given. Then we do not consider the impact of additional capacity on price.
} 
the variance of the output price. So there may be a great deal of ambiguity associated with the competition based on the output selling price $]^{6}$ Following Klibanoff et al. (2005), we describe the agent's behaviour towards ambiguity by a function $\phi$. An increasing and concave $\phi$ means that the agent is ambiguity averse. Similarly, ambiguity neutrality is characterized by the linear function $\phi$.

We associate a selling price $P_{i}$ with each state $i \in\{L W, H W, L S, H S\}$. A larger number of buyers is likely to be able to support a higher price, so we get that $P_{H W}>P_{L W}$ and $P_{H S}>P_{L S}$. Moreover, competition between fuel suppliers leads to a lower price, $P_{H W}>P_{H S}$ and $P_{L W}>P_{L S}$.

In period 0 , the agent has the opportunity to invest in plant in order to produce pretreated biomass. Let be $K \geq 0$, the stock of capital and the investment costs $I(K) . I$ is an increasing and convex function such that $I(0)=0$. As in Cairns (2009), we assume a sunk capital, i.e., a capital amount that is specific to the firm.

In period 1 , if the agent has invested $I(K)$ in period 0 , he has to choose his production $q$ which represents the units of torrefied biomass. This yields a pay-off equals to $P_{i} q$ in state $i \in\{L W, H W, L S, H S\}$. From this pay-off the cost of production $c(q, K)$ which is an increasing and convex function in $q$ and a decreasing and convex function in $K$ must be subtracted. Moreover, we assume that if $q>0$ then $c(q, 0)=\infty, c(0, K)=0$ for all $K>0$.

So, with a discount factor $\beta<1$, the agent's expected pay-off $V(K, q ; \psi, \theta)$ is expressed as follows:

$$
\begin{aligned}
V(K, q ; \psi, \theta)= & -I(K)+\beta \psi\left[\theta\left(P_{L S} q-c(q, K)\right)+(1-\theta)\left(P_{L W} q-c(q, K)\right)\right] \\
& \left.+\beta(1-\psi)\left[\theta\left(P_{H S} q-c(q, K)\right)\right)+(1-\theta)\left(P_{H W} q-c(q, K)\right)\right] .
\end{aligned}
$$

Likewise, considering the KMM ambiguity approach, the agent's expected pay-offs is given by: 7

$$
W(K, q, \psi, \theta)=\phi^{-1}\left(\int_{\underline{\theta}}^{\bar{\theta}} \phi(V(K, q, \psi, \theta)) d F(\theta)\right) .
$$

\section{Optimal decision making}

\subsection{Neutrality to ambiguity}

In this section, we consider that the agent is aware of the true value of $\theta$. In other words, there is uncertainty about the price variance and he believes that the probability associated with this uncertainty is relevant. In this case, we consider $W(K, q ; \psi, \theta)=V(K, q ; \psi, \theta) .8$

\footnotetext{
${ }^{6}$ In a context in which there are two uncertainties affecting simultaneously the level and the variability of the price, an agent is more sensitive to the price variability than to the price average. The demand uncertainty affects the perception of the average price while the competitive effect uncertainty affects the perception of the average price and mostly the variance price. Therefore, we assume an ambiguity associated with the competition effect uncertainty.

${ }^{7}$ Notice that we are interested by optimal decision and so the $\phi^{-1}$ has no influence on our results. We thank an anonymous referee for pointing out this property.

${ }^{8}$ More precisely, a neutral agent maximizes the expected pay-off $\phi(V(K, q ; \psi, \theta))$ where $\phi$ is linear function. For notation convenience, we assume $\phi$ is a scalar equal to 1 when agent is neutral to ambiguity.
} 
In period 0 , the agent has to determine his optimal stock of capital $K^{*}$ for producing pretreated biomass. Then, in period 1 , he could decide which quantity $q^{*}$ to produce. By consequence, we propose to solve this model through backward induction.

We define the expected price under demand uncertainty, the expected price under competitive effect uncertainty, and the expected price under both demand and competitive effect uncertainties, respectively, as follows:

$E_{\psi} P_{m}=\psi P_{L m}+(1-\psi) P_{H m}, E_{\theta} P_{j}=\theta P_{j S}+(1-\theta) P_{j W}$, and $E_{\psi \theta} P=\psi E_{\theta} P_{L}+(1-\psi) E_{\theta} P_{H}$.

with $j \in\{L, H\}$ and $m \in\{W, S\}$.

So the first order condition on quantity is:9

$$
\frac{\partial c(q, K)}{\partial q}=c_{q}=E_{\psi \theta} P
$$

If for all $q>0$ we get $V(K, q ; \psi, \theta) \leq 0$, i.e., if the project is never profitable, then the agent does not produce. On the other hand, if there exists $q>0$ such that $V(K, q ; \psi, \theta)>0$, the project is profitable for a certain level of production. This relation implies that $q$ is an implicit function of $K, q \equiv q(K)$.

Now, we study the optimal stock of capital $K$ which maximizes the expected pay-off $V(K, q(K) ; \psi, \theta)$. The condition is given by the solution of the following program:

$$
-\frac{d I(K)}{d K}+\beta \frac{d q(K)}{d K} E_{\psi \theta} P-\beta\left(c_{q} \frac{d q(K)}{d K}+c_{K}\right)=0 .
$$

Using equation (2), we obtain,

$$
\beta c_{K}=-\frac{d I(K)}{d K}=-I^{\prime}(K) .
$$

If for all $K>0$ we get $V(K, q(K) ; \psi, \theta) \leq 0$, i.e., if the project is never profitable, then the agent does not invest in it. On the other hand, if there exists $K>0$ such that $V(K, q(K) ; \psi, \theta)>0$, the project is profitable for certain level of investment.

As already mentioned in McDonald \& Siegel (1986) as in Gollier (2007), it is optimal for an agent to invest only if investment value exceeds his cost. Finally, the optimal decisions $\left(q^{*}, K^{*}\right)$ are defined by equations (2) and (3). We can summarize some static comparative results in the following lemma

Lemma 1 (i) A higher price, $P_{L W}, P_{H W}, P_{L S}$, and/or $P_{H S}$, always increases the level of production, $q^{*}$. That is not the case for the investment $K^{*}$, which increases when $\partial^{2} c\left(q^{*}, K^{*}\right) / \partial q \partial K<0$, decreases when $\partial^{2} c\left(q^{*}, K^{*}\right) / \partial q \partial K>0$ and does not vary when

\footnotetext{
${ }^{9}$ Here and hereafter, we will equally use the following notations: $\frac{\partial c(q, K)}{\partial K}=c_{K}, \frac{\partial^{2} c(q, K)}{\partial q \partial K}=c_{q K}$, $\frac{\partial^{2} c(q, K)}{\partial K^{2}}=c_{K K}$ and $\frac{\partial^{2} c(q, K)}{\partial q \partial q}=c_{q q}$.
} 
$\partial^{2} c\left(q^{*}, K^{*}\right) / \partial q \partial K=0$.

(ii) A higher subjective probability on the realization of a low number of buyers, $\psi$, and/or a higher subjective probability on the realization of a strong competition effect, $\theta$, always decreases the level of production, $q^{*}$. That is not the case for the investment $K^{*}$ which decreases when $\partial^{2} c\left(q^{*}, K^{*}\right) / \partial q \partial K<0$, increases when $\partial^{2} c\left(q^{*}, K^{*}\right) / \partial q \partial K>0$ and does not vary when $\partial^{2} c\left(q^{*}, K^{*}\right) / \partial q \partial K=0$.

\section{Proof.}

Part (i)

Increasing any price induces an increase of $E_{\psi \theta} P$. Conditions (2) and (3) imply $q^{*} \equiv q^{*}\left(E_{\psi \theta} P\right)$ and $K^{*} \equiv K^{*}\left(E_{\psi \theta} P\right)$. Denoting $\bar{P}$, the price expected value and differentiate (2) and (3), we obtain respectively, if $\partial^{2} c\left(q^{*}(\bar{P}), K^{*}(\bar{P})\right) / \partial q \partial K \neq 0$,

$$
\frac{d q^{*}(\bar{P})}{d \bar{P}}=\frac{1-c_{q K} \frac{\partial K^{*}(\bar{P})}{\partial P}}{c_{q q}}
$$

and

$$
\frac{d K^{*}(P)}{d P}=-\frac{c_{q K}}{\beta c_{q q} c_{K K}-\beta\left[c_{q K}\right]^{2}+c_{q q} I^{\prime \prime}(K)}
$$

With cost convexity assumption and the convexity of $I($.$) , we assume \beta c_{q q} c_{K K}-\beta\left[c_{q K}\right]^{2}+$ $c_{q q} I^{\prime \prime}(K)>0$. Then, if $c_{q K}<0, \partial K^{*}(\bar{P}) / \partial \bar{P}>0$ and $\partial q^{*}(\bar{P}) / \partial \bar{P}>0$.

\section{Part(ii)}

Conditions (2) and (3) imply $q^{*} \equiv q^{*}(\psi, \theta)$ and $K^{*} \equiv K^{*}(\psi, \theta)$. We differentiate (2) and (3) with respect to $\psi$ and $\theta$, we obtain respectively, if $\partial^{2} c\left(q^{*}(\theta, \psi), K^{*}(\theta, \psi)\right) / \partial q \partial K \neq 0$,

$$
\begin{aligned}
& \frac{\partial q^{*}(\theta, \psi)}{\partial \theta}=\frac{\psi\left(P_{L S}-P_{L W}\right)+(1-\psi)\left(P_{H S}-P_{H W}\right)-c_{q K} \frac{\partial K^{*}(\theta, \psi)}{\partial \theta}}{c_{q q}} \\
& \frac{\partial q^{*}(\theta, \psi)}{\partial \psi}=\frac{\theta\left(P_{L S}-P_{H S}\right)+(1-\theta)\left(P_{L W}-P_{H W}\right)-c_{q K} \frac{\partial K^{*}(\theta, \psi)}{\partial \psi}}{c_{q q}}
\end{aligned}
$$

and

$$
\begin{aligned}
\frac{\partial K^{*}(\theta, \psi)}{\partial \theta} & =-\frac{c_{q K}\left[\psi\left(P_{L S}-P_{L W}\right)+(1-\psi)\left(P_{H S}-P_{H W}\right)\right]}{c_{q q} c_{K K}-\left[c_{q K}\right]^{2}+c_{q q} I_{K K}} \\
\frac{\partial K^{*}(\theta, \psi)}{\partial \psi} & =-\frac{c_{q K}\left[\theta\left(P_{L S}-P_{H S}\right)+(1-\theta)\left(P_{L W}-P_{H W}\right)\right]}{c_{q q} c_{K K}-\left[c_{q K}\right]^{2}+c_{q q} I_{K K}}
\end{aligned}
$$

where $\psi\left(P_{L S}-P_{L W}\right)+(1-\psi)\left(P_{H S}-P_{H W}\right)<0$ and $\theta\left(P_{L S}-P_{H S}\right)+(1-\theta)\left(P_{L W}-P_{H W}\right)<0$. Then, $\partial q^{*}(\theta, \psi) / \partial \theta<0, \partial K^{*}(\theta, \psi) / \partial \theta<0, \partial q^{*}(\theta, \psi) / \partial \psi<0$ and $\partial K^{*}(\theta, \psi) / \partial \psi<0$ if $\partial^{2} c\left(q^{*}(\theta, \psi), K^{*}(\theta, \psi)\right) / \partial q \partial K<0$.

So the opportunity to sell each unit at a higher price, and then getting a higher pay-off, prompts the agent to produce more. This opportunity may come from an increase in the 
possible selling prices, a lower belief in the realization of a low number of buyers, and/or a lower belief in the realization of a strong competition effect.

Moreover, if the marginal production cost decreases in the capital investment, a higher price, a lower belief in the realization of a low number of buyers, and/or a lower belief in the realization of a strong competition effect increases the optimal level of investment in capital. Besides, if the capital investment has no impact on the marginal production costs then the prices and the two beliefs do not affect the agent's decision concerning the level of investment in capital. For simplicity in the following, we consider $c_{q K}>0$ and we can get that $K^{*}=0$ and $q^{*}=0$.

In addition, if the marginal production cost decreases with the capital investment, a higher price, a lower belief in the realization of a low number of buyers, and/or a lower belief on the realization of a strong competition effect prompts the agent to invest and produce.

So the effect of the capital investment on the marginal production cost plays a major role in the agent's decision concerning his investment in capital and production.

It is natural now to compare the situation of certainty with the situations in which there is one type of uncertainty (either demand uncertainty, or competitive effect uncertainty), and with the situation in which there are both types of uncertainty. To do so, we define the marginal rate of substitution associated with the cost as follows:

$$
T M S C(q, K)=-\frac{\frac{\partial c(q, K)}{\partial q}}{\frac{\partial c(q, K)}{\partial K}},
$$

which represents the increase in $K$ for which the cost is maintained when the agent produces one more unit. Using relations (2) and (3), we have

$$
\operatorname{TMSC}(q, K)=-\frac{c_{q}}{c_{K}}=\frac{E_{\psi \theta} P}{I^{\prime}(K)} .
$$

The situation of certainty, i.e. that in which the agent knows the number of buyers on the market and the severity of the market competition effect, corresponds to $E_{\psi \theta} P=P$. In this case, we denote by $q_{C}^{*}$ and $K_{C}^{*}$ the optimal quantity and investment .

The cases in which there is only one type of uncertainty: first, demand uncertainty, i.e., the agent has perfect knowledge of the level of the effect of market competition, correspond to $E_{\psi \theta} P=E_{\psi} P_{m}$ with $\theta=0$ or $\theta=1$. In the case of Demand Uncertainty, we denote by $q_{D U}^{*}$ and $K_{D U}^{*}$ the optimal quantity and investment; secondly, the competition effect uncertainty (i.e., the agent does not initially know the effect of competition but he knows the number of buyers of the future market) corresponds to $E_{\psi \theta} P=E_{\theta} P_{j}$ with $\psi=0$ or $\psi=1$. In the case of Competitive effect Uncertainty, we denote by $q_{C U}^{*}$ and $K_{C U}^{*}$ the optimal quantity and investment.

We first note that regardless of the certainty or uncertainty level, the agent never invests nor produces when he thinks that an increase in capital increases the cost of one more unit.

The lack of information on the true level of the price implies that the agent expects a lower value of the price than the realized one when it is high and expects an upper value of the price than the realized one when it is low. This directly impacts on the level of 
production, which decreases when the expected price is lower than the realized one, and increases when the expected price is higher than the realized one. Even though the level of capital investment is affected by this erroneous evaluation, the agent's decision also takes into account the effect on the cost of both the level of production and the level of capital invested. Actually, producing more leads the agent to choose a level of investment in capital that reduces his unit production cost. Then under uncertainty, the agent makes a lower (higher) investment when the expected price is lower (higher) than the realized one and the increase in capital decreases the cost of one more unit. Elder \& Serletis (2009, 2010) find empirical evidence that uncertainty about oil prices has tended to depress investment in Canada and United States. Our model could explain their result with considering that the investors expect at once a price that is lower than the true one and that an increase in capital reduces the marginal cost of production.

Moreover, under both uncertainties, the agent produces less when he does not know that the realized price is the highest, i.e., the number of buyers is high and there is little market competition. In this context, he invests less capital when he thinks that an increase in capital increases the cost of one more unit. On the contrary, the agent produces more when he does not know that the realized price is the lowest, i.e., the number of buyers is low and there is a strong market competition effect. Then, he invests more in capital when he thinks that an increase in capital decreases the cost of one more unit.

\subsection{Aversion to ambiguity}

In this section, we seek to understand how choices concerning capital and capacity investment are affected by ambiguity aversion. We then propose to compare the optimal production and capital investment decisions of an agent who is averse to ambiguity with those of an ambiguity neutral agent. To formalize the aversion to ambiguity, we consider that the 'right' value of the probability associated with the competition severity uncertainty $\theta$ may be unknown. The agent's belief, $\theta$, is then represented not as a single probability measure on the set of states but as a set of probability measures. Such a framework is relevant to the decision concerning investment and production; indeed, as quoted in Heath \& Tversky (1991): the ambiguity aversion is particularly strong in cases in which people feel that their competence in assessing the relevant probabilities is low.

We then extend the model by considering that $\theta$ is a random variable. The agent now associates a probability distribution $F(\theta)$ on $[\underline{\theta}, \bar{\theta}]$ which measures the subjective relevance of a particular $\theta$ probability. Following Klibanoff et al. (2005), we assume that the preferences of the agent indicate smooth ambiguity aversion. So, the agent considers that his expected pay-off is defined by equation (1):

$$
W(K, q, \psi, \theta)=\phi^{-1}\left(\int_{\underline{\theta}}^{\bar{\theta}} \phi(V(K, q, \psi, \theta)) d F(\theta)\right)
$$

with $\phi($.$) defined by an increasing and concave function when the agent is ambiguity averse.$

As mentioned previously, we consider the problem in two steps. First, we focus on the impact of ambiguity aversion on the optimal production, $\hat{q}^{*}$ and second on the optimal capital investment, $\hat{K}^{*}$. 
For a given stock of investment, the first order condition for production is given by:

$$
\int_{\underline{\theta}}^{\bar{\theta}} \phi^{\prime}(V(K, q ; \psi, \theta)) \frac{\partial V(K, q ; \psi, \theta)}{\partial q} d F(\theta)=0
$$

where

$$
\frac{\partial V(K, q ; \psi, \theta)}{\partial q}=\left(E_{\psi \theta} P-c_{q}\right)
$$

Proposition 1. For a given initial stock of capital investment, ambiguity aversion tends to decrease the agent's optimal level of production, $\hat{q}^{*}<q^{*}$.

Proof. We use the following notations:

$$
\begin{aligned}
& \Delta(q, \theta)=\phi^{\prime}(V(K, q ; \psi, \theta)) \\
& \Lambda(q, \theta)=E_{\psi \theta} P-c_{q} .
\end{aligned}
$$

By definition the covariance is:

$$
\operatorname{cov}(\Delta(q, \theta), \Lambda(q, \theta))=E(\Delta(q, \theta) \Lambda(q, \theta))-E(\Delta(q, \theta)) E(\Lambda(q, \theta)) .
$$

Then, with condition (5), we have

$$
E\left(\Delta\left(\hat{q}^{*}, \theta\right) \Lambda\left(\hat{q}^{*}, \theta\right)\right)=J\left(\hat{q}^{*}\right)=0
$$

Comparison to neutrality ambiguity case.

From condition (2), we know that $E\left(\Delta\left(q^{*}, \theta\right)\right)=0$ and then $\operatorname{cov}\left(\Delta\left(q^{*}, \theta\right), \Lambda\left(q^{*}, \theta\right)\right)=E\left(\Delta\left(q^{*}, \theta\right) \Lambda\left(q^{*}, \theta\right)\right)$

So if $\operatorname{cov}\left(\Delta\left(q^{*}, \theta\right), \Lambda\left(q^{*}, \theta\right)\right)<0$ that implies $E\left(\Delta\left(q^{*}, \theta\right) \Lambda\left(q^{*}, \theta\right)\right)<0$. This is equivalent to $J\left(q^{*}\right)<0=J\left(\hat{q}^{*}\right)$. Since $\phi$ is increasing and concave, $J($.$) is decreasing function and$ $q^{*}>\hat{q}^{*}$. The sign of covariance is given by differentiate $\Delta(q, \theta)$ and $\Lambda(q, \theta)$ with respect to $\theta$ where

$$
\frac{\partial \Lambda(q, \theta)}{\partial \theta}=\frac{\partial E_{\psi \theta}}{\partial \theta}<0
$$

and

$$
\frac{\partial \Delta(q, \theta)}{\partial \theta}=\phi^{\prime \prime}(V(K, q ; \psi, \theta)) \frac{\partial V(K, q ; \psi, \theta)}{\partial \theta}>0
$$

with $\phi^{\prime \prime}(V(K, q ; \psi, \theta))<0$ and $\partial V(K, q ; \psi, \theta) / \partial \theta<0$. Therefore, $\operatorname{cov}\left(\Delta\left(q^{*}, \theta\right), \Lambda\left(q^{*}, \theta\right)\right)<0$ and $q^{*}>\hat{q}^{*}$.

Let us now turn to the analyze of the agent's optimal investment in capital. Equation (5) implies that $\hat{q}^{*} \equiv \hat{q}^{*}(K)$ and the first order condition is:

$$
\int_{\underline{\theta}}^{\bar{\theta}} \phi^{\prime}\left(V\left(K, \hat{q}^{*}(K) ; \psi, \theta\right)\right) \frac{\partial V\left(K, \hat{q}^{*}(K) ; \psi, \theta\right)}{\partial K} d F(\theta)=0
$$


where

$$
\frac{\partial V\left(K, \hat{q}^{*}(K) ; \psi, \theta\right)}{\partial K}=-I^{\prime}(K)+\beta \frac{d \hat{q}^{*}(K)}{d K} E_{\psi \theta} P-\beta\left(c_{q} \frac{d \hat{q}^{*}(K)}{d K}+c_{K}\right) .
$$

Proposition 2. If $\partial^{2} c\left(q^{*}, K^{*}\right) / \partial q \partial K<0$ then ambiguity aversion tends to decrease the agent's optimal investment level, $\hat{K}^{*}<K^{*}$.

Proof. Similar to the proof of Proposition 1 with conditions (3) and (7).

Aversion to ambiguity concerning the competition effect leads the agent to reduce his investment in capital and his production. Actually, the agent has doubts about its own subjective beliefs on the competition effect. This adds a new uncertainty dimension for him and discourages him from investing and producing. Ambiguity aversion then restrains investment and production in the new process. This may have drastic consequences on the development of emerging processes.

\section{Numerical analysis}

The empirical analysis is based on the French biomass pre-treatment industry. The case of France is a particularly interesting subject of study, because active research studies are being conducted on second generation biofuel technologies (ADEME, 2009). One of the pilot programmes in which five French partners and one German partner participate, has launched BioTfueL, a million Euro project that uses the Fischer-Tropsch process to convert torrefied wood biomass into drop-in renewable fuel. This group will launch pilot projects in France that will commence in 2012. The domestic biomass resources available are also large.10 Prospects for the diffusion of torrefaction technology in such a dynamic and expanding market are also of particular interest if the economical profitability is to be enhanced.

To determine the profit flow the firm receives when the project is implemented, we suppose, as is frequently done, that sunk investment costs are linear: $I(K)=p_{K} K, p_{K}>0$ and $I^{\prime}(K)=p_{K}$ with $p_{K} \in[0,1]$, the investment coefficient (Cairns, 2009). The quantity of pre-treated biomass is a function of the amount of capital, $K$, that have to be paid for the installation of a production facility. Using (4), we can easily define different probability thresholds, $\theta$ and $\psi$ by comparing different cases.

\subsection{Determination of the cost function}

Like Cairns (2009) and Tsatsaronis \& Park (2002), we consider the avoidable cost of production $c(q, K)$ as a function of the amount of capital, $K$ and the output production, $q$. The avoidable costs are commonly calculated by subtracting the unavoidable cost from the respective total cost excluding the sunk cost $I(K)$ such that:

$$
c(q, K)=c^{T}(q, K)-c^{U N}(q, K)
$$

\footnotetext{
${ }^{10}$ The French potential of forest residues was estimated at over $30 \mathrm{Mt}$ per year available for energetic use in 2015 (MEEDDAT, 2010).
} 
where $c^{T}(q, K)$ is the total cost and $c^{U N}(q, K)$, the unavoidable costs.

The total cost function is a convex function composed of the capital costs and the production costs. We use a limited development at the order one of the translog function to represent the cost minimizing behaviour of the agent who uses the amount $K$ of capital to produce a quantity $q$ of output. For the torrefaction technology, the cost function is:

$$
\ln \left(c^{T}(q, K)\right)=a_{1}+a_{2} \ln (q)+a_{3} \ln (K)+a_{4} \ln (q) \ln (K)
$$

where $a_{1}>0$, is a fixed cost, $a_{2}$ and $a_{3}$ are the cost elasticity of the production and the capital respectively, $a_{4}$, is the cross elasticity between production and capital. We assume that the unit costs of production are increasing in accumulated production so $a_{2}>0$ and the investment costs of invested capital $K$ are decreasing in accumulated capital so $a_{3}<0$. The data on operating costs of a torrefaction plant were taken from the existing literature and consists of engineering estimates. The technology exists today but it is tested at pilot scale, so we estimate our coefficients on the basis of economic data for different possible capacities of units (c.f. table (B.1) in appendix). We assume that unit runs at full capacity. The estimates are presented in table B.2 in appendix.

We then determine the unavoidable cost rate related to the production and the investment as follows (Tsatsaronis \& Park, 2002). Due to technical limitations imposed by the availability and/or costs of materials and manufacturing methods, a maximum value of the mass efficiency of the torrefaction process cannot be exceeded regardless of the amount invested. This efficiency is achieved at the point where the investment cost becomes infinite. This point determines the unavoidable destruction of raw biomass per unit of torrefied biomass . Thus, we could determine the cost rate associated with the unavoidable raw biomass destruction $Z_{q}^{U N}$. Similarly, the unavoidable investment costs per unit of torrefied biomass, $Z_{K}^{U N}$, are obtained by considering an extremely inefficient version of the technology, that is a version that would never be feasible in practice because of the very high biomass costs associated with it 11 We assume that the percentage of the total costs that cannot theoretically be avoided, in view of today's technology and economic environment of the torrefaction, technology is between $20 \%$ and $50 \%$ (Tsatsaronis \& Park, 2002). We take an average unavoidable cost $Z^{U N}$ such as $Z^{U N}=Z_{q}^{U N}=Z_{K}^{U N}=35 \%$. Then the avoidable costs are calculated by subtracting the unavoidable cost rates from the respective cost rates:

$$
c(q, K)=\left(1-Z^{U N}\right) e^{a_{1}+a_{4} \ln (K) \ln (q)} K^{a_{3}} q^{a_{2}} .
$$

Then we have to select an appropriate discount rate. It is an important topic in investment decision 12 Various ways of calculating discount rates adjusted for risk, have been proposed by Trigeorgis (1996). Schmit et al. (2009) assume a discount rate of $8 \%$ to reflect a relatively high credit risk for the investment in ethanol plant, whereas Uslu et al. (2008) chooses a discount rate of $12.5 \%$ for an investment in torrefaction. The discount rate of the

\footnotetext{
${ }^{11}$ In practical applications, this term is determined by arbitrarily selecting a set of parameters for this technology that lead to a very inefficient solution and by estimating the investment costs for this solution.

${ }^{12}$ See Kumbaroglu et al. (2008) for references.
} 
refinery unit is between 8 and 10\% (Dangl, 1999; Felfli et al., 2005). In our analysis, we assume it is equal to $10 \%$ because torrefaction units will supply BtL and refinery units. We will vary this rate in the sensitive analysis.

We illustrate the results determined in section 3 for an ambiguity neutral agent and an ambiguity averse agent.

\subsection{Agent's preferences}

\subsubsection{Ambiguity-neutral agent}

According to operating data for torrefaction plant, the marginal cost of production decreases in $K$ and increases in $q$ (table $(\overline{B .1})$ ). Furthermore, the cost function does not vary with the number of uncertainty such that $c\left(q_{C}^{*}, K_{C}^{*}\right)=c\left(q^{*}, K^{*}\right)$ and $c\left(q_{D U}^{*}, K_{D U}^{*}\right)=c\left(q_{C U}^{*}, K_{C U}^{*}\right)$. To illustrate our results, we consider the following scenario: $p_{K}=0.5{ }^{13} \theta=0.5, \psi=0.5{ }^{14}$ We take the prices of torrefied biomass collected during a survey conducted among potential buyers of torrefied biomass in France such as $P_{L W}=100$ Euros/t, $P_{H W}=200$ Euros $/ \mathrm{t}$, $P_{L S}=80$ Euros $/ \mathrm{t}$ and $P_{H S}=148$ Euros $/ \mathrm{t} \cdot{ }^{15}$ From (2) and (3), we determine the optimal level of production and investment for the situation in which there are both types of uncertainty, the situation in which there is certainty and the situation in which there is only one uncertainty. The results are summed up in table B.3p for the different cases $P_{i}=P_{j m}$ for $j \in\{L, H\}$ and $m \in\{W, S\}$.

Taking into account of the operating costs, the optimal investment in capital, $K^{*}$ and the optimal levels of production, $q^{*}$ are ranked to the uncertainty which the agent faces.

We observe the asymmetric effects of uncertainty on the optimal amount of investment and optimal production. We show that the effect of number of buyers related uncertainty is stronger than that of the competition related uncertainty as the investment and the production levels are higher. This is true when, in the case of certainty, the effect of competition is weak and the number of buyers is low, or high if and only if the agent's subjective probability on the weak competition is lower than a certain threshold. Furthermore, if in the situation of certainty the agent knows the competition effect is weak and the number of buyers is high, the combination of both types of uncertainty leads him to invest less. He behaves similarly if the number of buyers is low in the certainty case if and only if his subjective probability concerning number of buyers is lower than a certain threshold (cases $P_{L W}=100$ Euros/t and $P_{H W}=200$ Euros/t of table (B.3p).

Secondly, the effect of the competition related uncertainty is stronger than the uncertainty concerning the demand uncertainty as the investment and production levels are higher. This is true when in the case of certainty the competition is strong and the number of buyers is high, or low if and only if the agent's prior belief concerning the weak competition is higher than a certain threshold. Besides, if in the certainty case the agent knows the competition is strong and the market size is low, the combination of both types of uncertainty leads him

\footnotetext{
${ }^{13}$ We study the effect of different values of this parameter in the sensitivity analysis.

${ }^{14}$ We take a average value between 0 and 1 for $\psi$ and $\theta$.

${ }^{15}$ These values were determined during a confidential survey conducted in 2010 among the French energy companies which are potential consumers of torrefied biomass. For more details, please contact the authors.
} 
to invest more. If the market size is high in the certainty case, he has the same behaviour if and only if his prior belief on market size is higher than a certain threshold (cases $P_{H S}=148$ Euros/t and $P_{L S}=80$ Euros/t of table (B.3)).

Finally, we study the effect of increasing and decreasing the investment coefficient. We sum up the results in table (B.4) in appendix for different value of $p_{K} \in[0,1]$. We notice that $K^{*}$ decreases when $p_{K}$ increases whether there is one or two types of uncertainty. As proved in the Lemma 1, a higher investment coefficient increases the cost of investment so the agent decreases his capital investment.

\subsubsection{Ambiguity-averse agent}

We now illustrate propositions 1 and 2 to examine the difference ambiguity causes in the results. Following Judd (1999); Miranda \& Fackler (2004), we use a Gaussian quadrature to produce the Legendre-Gauss weights and nodes for computing the integral of the continuous function $W$ on interval $[\underline{\theta}, \bar{\theta}]$ with $\underline{\theta}=0$ and $\bar{\theta}=1$. We use a beta distribution $B(\theta ; \eta, \mu)$ with the parameter $\eta=0.5$ and $\mu=0.5$ to specify the probability distribution over the set of plausible distribution of the competitive effect. Indeed, the beta distribution is often used to describe the distribution of an unknown probability value, typically, as the prior distribution over a probability parameter. It is defined on the interval $[0,1] . \eta$ and $\mu$ give the shape of the probability density function. If $\eta<1$ and $\mu<1$, the beta density function is U-shaped and symmetric about $1 / 2$ if $\eta=\mu$. Following Klibanoff et al. (2005); Engle-Warnick et al. (2008), we consider a constant absolute ambiguity aversion (CAAA) utility function such as:

$$
\phi(V(K, q ; \psi, \theta))=\left\{\begin{aligned}
\frac{1-e^{-\tau V}}{1-e^{-\tau}} & \text { if } \tau>0 \\
V & \text { if } \tau=0
\end{aligned}\right.
$$

where $\tau$ is the coefficient of ambiguity aversion. For the figure clarity, we take $\tau=15$ to compare the case of an agent who is highly averse to ambiguity with that of an ambiguity neutral agent 16 Figures (A.1) and A.2 below show the marginal payoffs, $\partial W(q, K ; 0.5, \theta) / \partial q$ in function to $\mathrm{q}$ to determine $q^{*}$ and $\partial W(q(k), K ; 0.5, \theta) / \partial K$ in function to $\mathrm{K}$ to determine $K^{*}$ for both an ambiguity neutral and an ambiguity averse agents.

\section{[Insert figures A.1 and A.2 ]}

The marginal values are decreasing in $q$ and $K$. Thus we find that an ambiguity averse agent produces less than an ambiguity-neutral agent and invests less as defined in the proposition 1 and 2. The results are the same for different value of $\tau$. Due to ambiguity, an agent who invest in biomass torrefaction facilities chooses a lower capacity for his units than he would if he were ambiguity neutral. Ambiguity aversion leads the investor to evaluate probabilities distribution according to the least-favourable state, in this case the lowest pay-off.

\footnotetext{
${ }^{16}$ The results are robust for any other lower value of $\tau$. In the portfolio choice examples proposed by (Klibanoff et al. 2005), the coefficient of ambiguity aversion varies between 1 and 20. For sake of clarity, we then take $\tau=15$.
} 
This behaviour could have consequences on the development of emerging BtL process. Indeed, as mentioned before, the pre-treatment could enhance the deployment of BtL process because it can improve the economics of the overall production chain. If the producer invests less, the buyer takes the risk of not being supplied the right quantity. The buyer of the torrefied biomass perceives uncertainty about the availability of their inputs. They would be reluctant to invest in the new renewable energy process.

Finally, we study the effect of an increase and decrease in the investment coefficient $p_{K}$ when the agent is ambiguity averse. Figure A.3 below shows the marginal payoffs $\partial W(q(K), K ; 0.5, \theta) / \partial K$ in function to $\mathrm{K}$ for different values of $p_{K} \in[0,1]$.

[Insert figure A.3)]

We notice that $\hat{K}^{*}$ decreases when $p_{K}$ increases whatever the coefficient of ambiguity aversion level. A higher investment coefficient increases the cost of investment so the agent decreases his capital investment when the agent is ambiguity averse.

\subsection{Parameter sensitive analysis}

4.3.1. Sensitivity of the optimum strategy as regards the unavoidable cost rate $Z^{U N}$

In the reference example, the percentage of total costs that could be not avoided in view of today's technology and economic environment, is an average of maximum and minimum percentages that are possible today. The reference unit produced torrefied biomass relatively expensively compared with units for which the unavoidable cost rate is higher but the mass efficiency of the torrefaction is also better. Increasing the unavoidable cost rates should increase the competitive advantage of a high-output capacity due to the fact the avoidable cost is lower, but regardless the amount invested, the mass efficiency is lower. This can be verified in the table $(\mathrm{B} .5)$ in which tests are made for minimum and maximum values in the range of possible unavoidable cost rates determined for this torrefaction process. A decrease in the proportion of the unavoidable cost reduces the profitability by increasing the avoidable cost price and therefore deters the entrepreneur for investing in high capacity. An increase in the unavoidable cost rate increases the optimal capital investment. However, whatever the unavoidable cost rate $Z^{U N}$, the ranking of optimal investment in capital is unchanged.

\subsubsection{Variation in the discount rate}

In our reference simulation, we considered a discount rate of $10 \%$ per year. In this section, we examine the effect of an increase in the discount rate from $10 \%$ to $12 \%$ and a decrease from $10 \%$ to $8 \%$. A change in the discount rate modifies the optimum investment strategy. A higher discount rate penalizes the waiting time and therefore encourages the entrepreneur to invest earlier. Indeed, the sensitive analysis (c.f. table (B.6P) shows the increase (decrease) in the discount rate leads to a high (low) investment in capital. Nevertheless, whatever the discount rate, the ranking of optimal investments in capital is unchanged. 


\section{Conclusion}

In this paper, we assess the impact of two types of uncertainty and of the ambiguity aversion of the agent on his investment and production strategy. We develop a formal model for decision making in which agents are neutral to risk and averse to ambiguity about the true distribution of the competitive effect. We analyze the optimal capacity and production choices in this model. Using an analytical approach and numerical analysis, we first note that whatever the certainty or uncertainty context, the agent never invests or produces when he thinks that an increase in capital increases the cost of one more unit. Moreover, the agent's capital investment decision depends on the effects of the amount of capital invested, of the level of production on the cost and on the uncertainty to which the agent is confronted. Then, we observe asymmetric effects of demand uncertainty (in terms of number of buyers) and competitive effect uncertainty on the optimal amount of investment and optimal production. Finally, in the presence of ambiguity about the competition effect, agents will invest less in their units and their level of production is lower. The main feature of this model is that it helps to understand the behaviour of an agent who faces uncertainty about the market size and market competition if he is averse to ambiguity. This paper emphasizes the need to reduce the effects of ambiguity in the European policy framework that encourages the development of renewable energy production. The introduction of long-term contracts could contribute to reducing them. Actually, these contracts could be defined as agreements between a pretreated biomass producer (seller) and a renewable energy generator owner (buyer) for the purchase of torrefied biomass. By hedging against price volatility, these contracts would reduce the ambiguity impact of the competition effect. They could take the forms of competitive procurement process or bilateral contract negotiation (see Michaud (2010)).

An attractive feature of the model is to determine how the risk and ambiguity aversions of the buyer will affect the investment strategy of torrefied biomass producers. Finally, it will be important to check empirically, with potential agents (private forest owners, cooperatives...) the theoretical results obtained in our model and to evaluate the degree of their ambiguity aversion. 
ADEME (2009). Grenelle Environnement : Fonds démonstrateur de recherche. Descriptif des projets validés par le Comité de pilotage. Technical report, Agence de l'Environnement et de la Maitrise de l'Energie.

Bond, S., Moessner, R., Mumtaz, H., \& M.Syed (2005). Microeconometric Evidence on Uncertainty and Investment. Mimeo, Institute for financial studies.

Cairns, R. D. (2009). Sunk Cost and Cost Functions. mimeo, Departement of Economics, McGill University.

Camerer, C. (1999). Ambiguity-Aversion and Non-Additive Probability: Experimental Evidence, Models and Applications., chapter Uncertain Decisions: Bridging Theory and Experiments, (pp. 53-80). Kluwer Academic Publishers.

Carruth, A., Dickerson, A., \& A.Henley (2000). What do we know about investment under uncertainty? Journal of Economic Surveys, 14, 119-153.

Dangl, T. (1999). Investment and capacity choice under uncertain demand. European Journal of Operational Research, 117, 415-428.

Dixit \& Pindyck (1994). Investment under uncertainty. Princeton University Press.

Elder, J. \& Serletis, A. (2009). Oil price uncertainty in canada. Energy Economics, 31(6), 852-856. Energy Sector Pricing and Macroeconomic Dynamics.

Elder, J. \& Serletis, A. (2010). Oil price uncertainty. Journal of Money, Credit, and Banking, 42(6), 1137-1159.

Ellsberg, D. (1961). Risk, ambiguity, and the savage axioms. Quaterly Journal of Economics, $110(3), 585-603$.

Engle-Warnick, J., Escobal, J., \& Laszlo, S. (2008). Ambiguity aversion and portfolio choice in small-scale peruvian farming. mimeo.

Etner, J., Jeleva, M., \& Tallon, J.-M. (2010). Decision theory under uncertainty. Journal of Economic Surveys.

Fan, Y. \& Zhu, L. (2010). A real options based model and its application to china's overseas oil investment decisions. Energy Economics, 32(3), 627-637.

Felfli, F. F., Luengo, C. A., \& Rocha, J. D. (2005). Torrefied briquettes: technical and economic feasibility and perspectives in the brazilian market. Energy for Sustainable Development, 9, 23-29.

Fellner, W. (1961). Two propositions in the theory of induced innovations. The Economic Journal, 71(282), 305-308.

Fellner, W. (1965). Probability and Profit. Yale University. 
Gollier, C. (2006). Does ambiguity aversion reinforce risk aversion? applications to portfolio choices and asset prices. In Séminaire d'Economie Théorique: Université de Toulouse 1 Sciences Sociales.

Gollier, C. (2007). Comment intégrer le risque dans le calcul économique? Revue d'économie politique, 117(2/2007), 209-223.

Heath, C. \& Tversky, A. (1991). Preference and belief: Ambiguity and competence in choice under uncertainty. Journal of Risk and Uncertainty, 4, 5-28.

Henry, C. (1974). Investment decisions under uncertainty: The "irreversibility effect". The American Economic Review, 64(6), 1006-1012.

Isik, M., Coble, K. H., Hudson, D., \& c, L. O. H. (2003). A model of entry-exit decisions and capacity choice under demand uncertainty. Agricultural Economics.

Judd, K. L. (1999). Numerical methods in economics. MIT Press.

Klibanoff, P., Marinacci, M., \& Mukerji, S. (2005). A smooth model of decision making under ambiguity. Econometrica, 73(6), 1849-1892.

Kulatilaka, N. \& Perotti, E. (1998). Strategic growth options. Management Science, 44, 1021-1031.

Kumbaroglu, G., Madlener, R., \& Demirel, M. (2008). A real options evaluation model for the diffusion prospects of new renewable power generation technologies. Energy Economics, 30(4), 1882-1908.

McDonald, R. \& Siegel, D. (1986). The value of waiting to invest. The Quarterly Journal of Economics, 101(4), 707-728.

MEEDDAT (2010). La fiscalité des biocarburants en France. Technical report, Ministère de l'Ecologie, de l'Energie, du Développement Durable et de l'Amménagement du territoire, http://www.developpement-durable.gouv.fr/La-fiscalite-des-biocarburants-en.html.

Michaud, P. R. (2010). Long-term Renewable Energy Contracts, Net-Metering, and Ocean Wind Initiatives in New England. Technical report.

Miranda, M. J. \& Fackler, P. L. (2004). Applied computational economics and finance. The MIT Press.

Mohn, K. \& Misund, B. (2009). Investment and uncertainty in the international oil and gas industry. Energy Economics, 31(2), 240-248.

Murto, P. (2006). Timing of investment under technological and revenue-related uncertainties. Journal of Economic Dynamics and Control, 31(5), 1473 - 1497. 
Murto, P., Näsäkkälä, E., \& Keppo, J. (2004). Timing of investments in oligopoly under uncertainty: A framework for numerical analysis. European Journal of Operational Research, $157(2), 486-500$.

Sarkar, S. (2000). On the investment-uncertainty relationship in a real options model. Journal of Economic Dynamics and Control, 24(2), 219-225.

Schmit, T. M., Luo, J., \& Tauer, L. W. (2009). Ethanol plant investment using net present value and real options analyses. Biomass 86 Energy, 33, 1442-1451.

Slovic, P. \& Tversky, A. (1974). Who accepts savage's axiom? Behavioral Science, 19, $368-373$.

Sutton, J. (1991). Sunk costs and Market structure. MIT Press.

Trigeorgis, L. (1996). Real Options. MIT Press.

Tsatsaronis, G. \& Park, M.-H. (2002). On avoidable and unavoidable exergy destructions and investment costs in thermal systems. Energy Conversion and Management, 43(9-12), $1259-1270$.

Uslu, A., Faaij, A. P., \& Bergman, P. (2008). Pre-treatment technologies, and their effect on international bioenergy supply chain logistics. techno-economic evaluation of torrefaction, fast pyrolysis and pelletisation. Energy, 33(8), 1206-1223. 


\section{Appendix A. Figures}

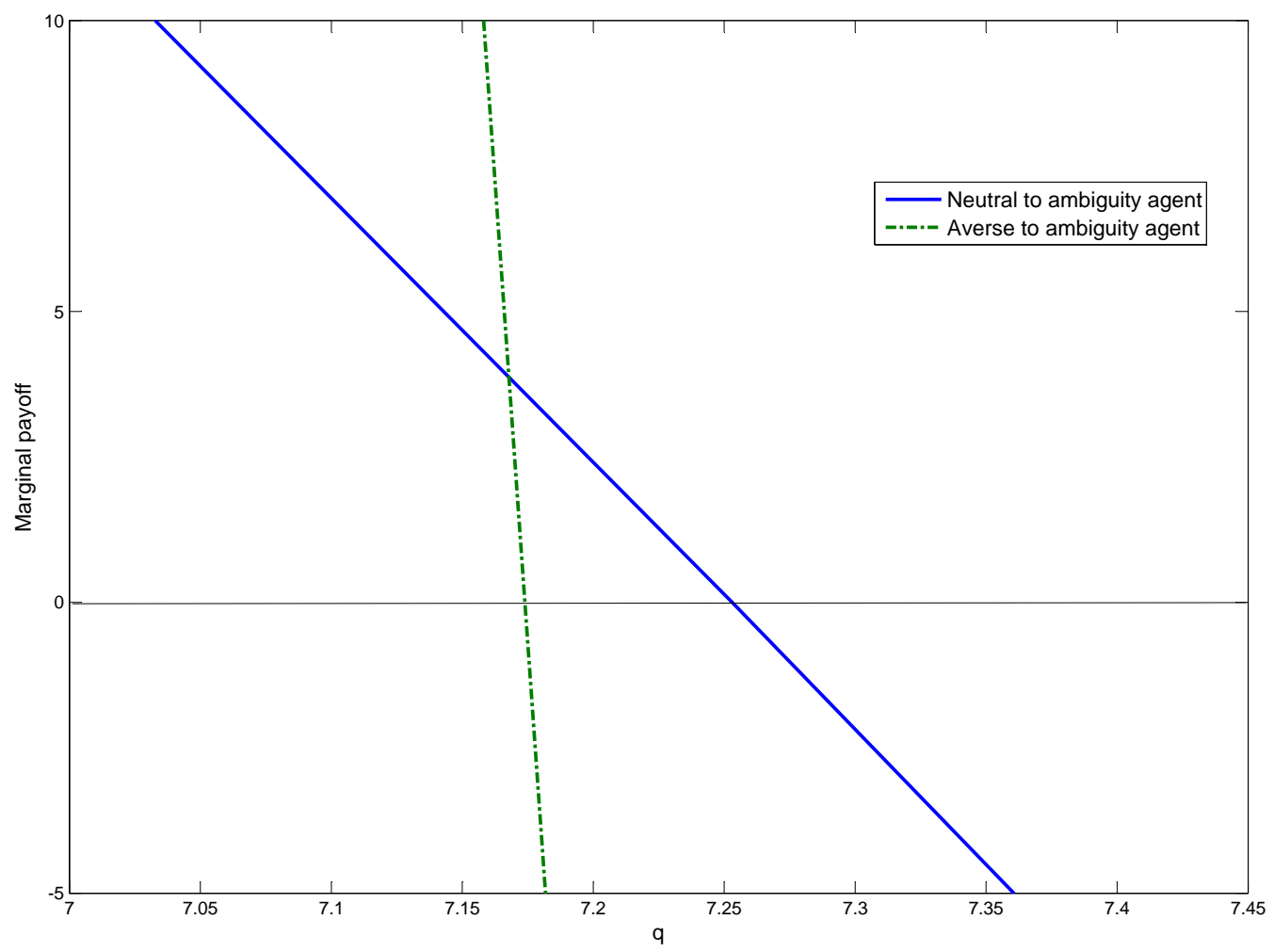

Figure A.1: The marginal payoff $\partial W(6.34, q ; 0.5, \theta) / \partial q$ in function to $q$. Calculated with $\beta=0.1, \tau=15$ and $p_{K}=0.5$. 


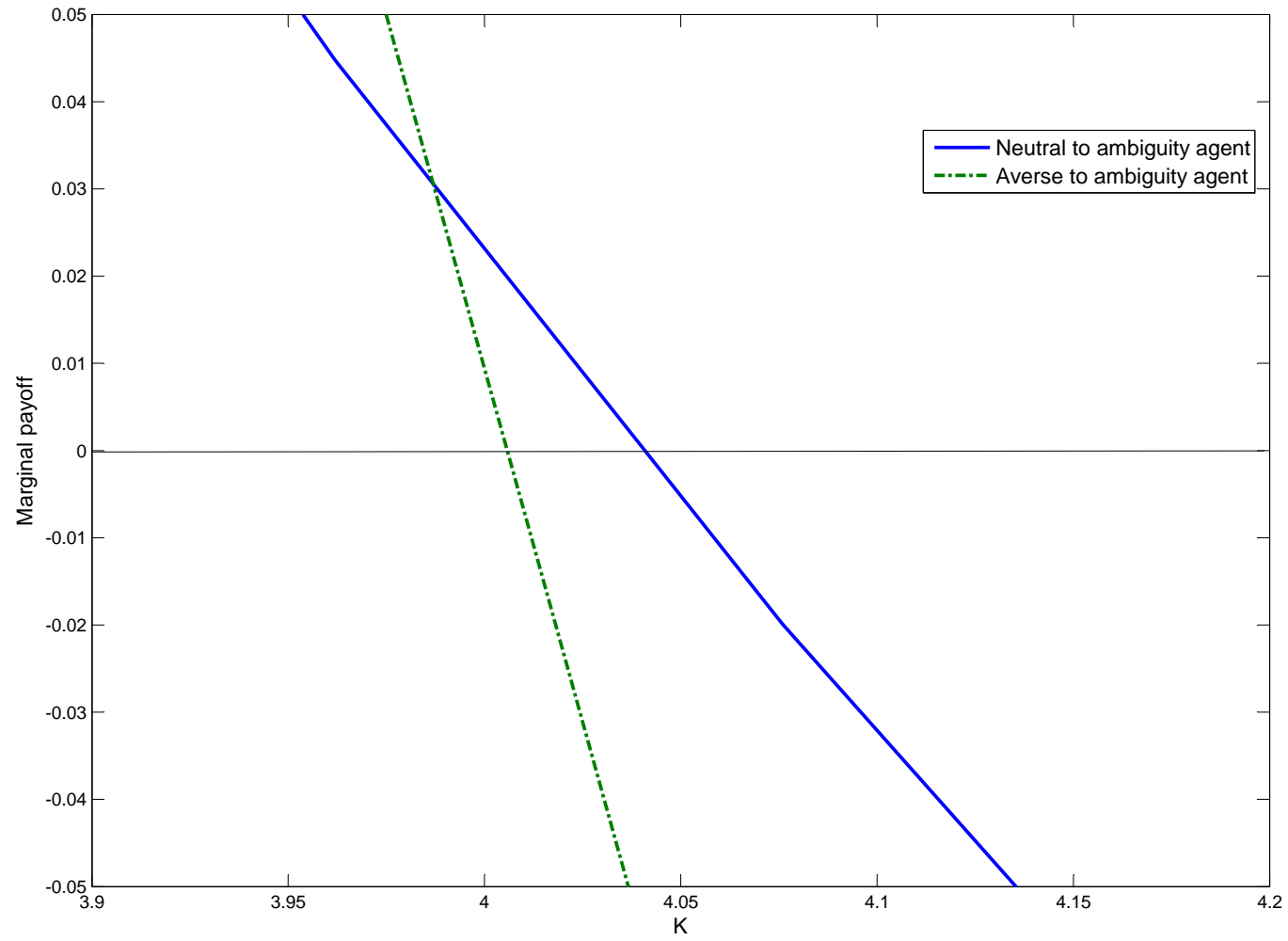

Figure A.2: The marginal payoff $\partial W(K, q ; 0.5, \theta) / \partial K$ in function to $K$ for $\hat{q}^{*}(K)=7.18$ and $q^{*}(K)=7.26$. Calculated with $\beta=0.1, \tau=15$ and $p_{K}=0.5$. 


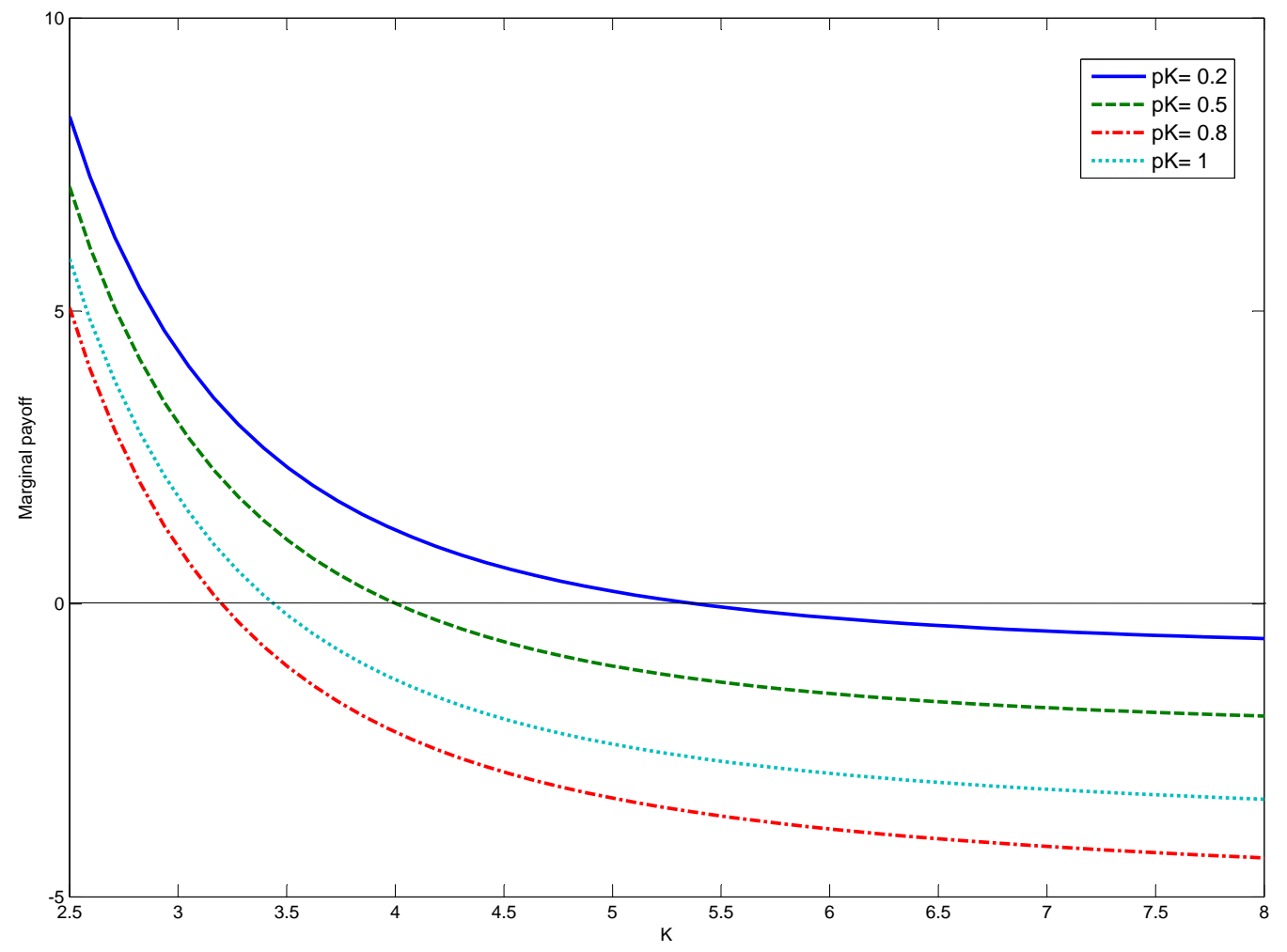

Figure A.3: The marginal payoff $\partial W(K, q ; 0.5, \theta) / \partial K$ in function to $K$ for $\hat{q}^{*}(K)=7.18$ for different values of $p_{K}$ when the agent is ambiguity averse. Calculated with $\beta=0.1$ and $\tau=15$. 


\section{Appendix B. Tables}

Table B.1: Operating expenses for the different scale of unit

\begin{tabular}{llccc}
\hline Parameters & Units & \multicolumn{3}{c}{ Capacity } \\
\cline { 3 - 4 } & t/an & 80000 & 200000 & 400000 \\
\hline$K$ & MEuros & 7.5 & 15.6 & 27.18 \\
$\frac{\partial c(q, K)}{\partial K}$ (in absolute value) & Euros/t & 35.6 & 29.6 & 25.8 \\
$\frac{\partial c(q, K)}{\partial q}$ & Euros/t & 26 & 20.9 & 20.9 \\
Biomass cost $(1)$ & Euros/t & 137 & 137 & 137 \\
Total marginal cost & Euros/t & 198.6 & 187.6 & 183.6 \\
\hline
\end{tabular}

(1) We assume that biomass is sold at the same price regardless of unit capacity.

Table B.2: Estimation results for the cost function parameters

\begin{tabular}{cc}
\hline Parameters & Values \\
\hline$a_{1}$ & 1 \\
$a_{2}$ & 2.33 \\
$a_{3}$ & -2.33 \\
$a_{4}$ & 0.12 \\
\hline
\end{tabular}


Table B.3: Optimal level of production and investment in function of the uncertainties for $P_{L W}=100$ Euros $/ \mathrm{t}, P_{H W}=200$ Euros $/ \mathrm{t}, P_{L S}=80$ Euros $/ \mathrm{t}$ and $P_{H S}=148$ Euros $/ \mathrm{t}$

\begin{tabular}{|c|c|c|c|c|c|c|}
\hline Case & Number of uncertainties & $\psi$ & $\theta$ & $q^{1}$ & $K^{2}$ & Ranking of optimal levels of $q$ and \\
\hline & Two Uncertainties & 0.5 & 0.5 & 12.96 & 6.45 & \\
\hline \multirow{3}{*}{$P_{i}=P_{L W}$} & Certainty $(\mathrm{C})$ & 1 & 1 & 13.91 & 6.84 & \multirow{3}{*}{$\begin{array}{c}q_{D U}^{*}>q_{C}^{*}>q^{*}>q_{C U}^{*} \\
K_{D U}^{*}>K_{C}^{*}>K^{*}>K_{C U}^{*}\end{array}$} \\
\hline & Competitive effect (CU) & 1 & 0.5 & 11.83 & 5.98 & \\
\hline & Demand (DU) & 0.5 & 1 & 15.39 & 7.44 & \\
\hline \multirow{3}{*}{$P_{i}=P_{H W}$} & Certainty $(\mathrm{C})$ & 0 & 1 & 16.79 & 8.00 & \multirow{3}{*}{$\begin{array}{c}q_{C}^{*}>q_{D U}^{*}>q_{C U}^{*}>q^{*} \\
K_{C}^{*}>K_{D U}^{*}>K_{C U}^{*}>K^{*}\end{array}$} \\
\hline & Competitive effect(CU) & 0 & 0.5 & 14.03 & 6.88 & \\
\hline & Demand(DU) & 0.5 & 1 & 15.39 & 7.44 & \\
\hline \multirow{3}{*}{$P_{i}=P_{L S}$} & Certainty (C) & 1 & 0 & 9.49 & 5.00 & \multirow{3}{*}{$\begin{array}{c}q^{*}>q_{C U}^{*}>q_{D U}^{*}>q_{C}^{*} \\
K^{*}>K_{C U}^{*}>K_{D U}^{*}>K_{C}^{*}\end{array}$} \\
\hline & Competitive effect(CU) & 1 & 0.5 & 11.83 & 5.98 & \\
\hline & Demand (DU) & 0.5 & 0 & 10.21 & 5.31 & \\
\hline \multirow{3}{*}{$P_{i}=P_{H S}$} & Certainty (C) & 0 & 0 & 10.90 & 5.59 & \multirow{3}{*}{$\begin{array}{c}q_{C U}^{*}>q^{*}>q_{C}^{*}>q_{D U}^{*} \\
K_{C U}^{*}>K^{*}>K_{C}^{*}>K_{D U}^{*}\end{array}$} \\
\hline & Competitive effect (CU) & 0 & 0.5 & 14.04 & 6.88 & \\
\hline & Demand (DU) & 0.5 & 0 & 10.21 & 5.31 & \\
\hline
\end{tabular}

(1) In ton per hour; (2) In MEuros.

Table B.4: Sensitive analysis as regards the investment coefficient, $p_{K}$ for $\theta=0.5, \psi=0.5$ in case $P_{i}=P_{H S}=148$ Euros $/$ t.

\begin{tabular}{llcccc}
\hline Number of uncertainties & $K^{1}$ & \multicolumn{5}{c}{ Values of $p_{K}$} \\
\cline { 3 - 6 } & & 0.2 & 0.5 & 0.8 & 1 \\
\hline Certainty (C) & $K_{C}^{*}$ & 8.73 & 6.45 & 5.52 & 5.13 \\
Two Uncertainties & $K^{*}$ & 7.56 & 5.59 & 4.79 & 4.46 \\
Competitive effect (CU) & $K_{C U}^{*}$ & 9.33 & 6.88 & 5.89 & 5.47 \\
Demand(DU) & $K_{D U}^{*}$ & 7.16 & 5.31 & 4.55 & 4.23 \\
\hline
\end{tabular}

(1) In MEuros. 
Table B.5: Sensitive analysis as regards the unavoidable cost rate for $\theta=0.5, \psi=0.5$ in $P_{i}=P_{H S}=148$ Euros/t.

\begin{tabular}{|c|c|c|c|c|}
\hline$\overline{Z^{U N}}$ & Number of uncertainties & $q^{1}$ & $K^{2}$ & Ranking of optimal levels of $q$ and $K$ \\
\hline \multirow{4}{*}{$20 \%$} & Two Uncertainties & 11.39 & 6.21 & \multirow{4}{*}{$q_{C U}^{*}>q^{*}>q_{C}^{*}>q_{D U}^{*}$} \\
\hline & Certainty (C) & 9.58 & 5.39 & \\
\hline & Competitive effect (CU) & 12.33 & 6.63 & \\
\hline & Demand (DU) & 8.97 & 5.12 & \\
\hline \multirow{4}{*}{$50 \%$} & Two Uncertainties & 15.26 & 6.77 & \multirow{4}{*}{$q_{C U}^{*}>q^{*}>q_{C}^{*}>q_{D U}^{*}$} \\
\hline & Certainty $(\mathrm{C})$ & 12.84 & 5.87 & \\
\hline & Competitive effect (CU) & 16.52 & 7.23 & \\
\hline & Demand (DU) & 12.03 & 5.56 & \\
\hline
\end{tabular}

(1) In ton per hour; (2) In MEuros.

Table B.6: Sensitive analysis as regards the discount rate for $\theta=0.5, \psi=0.5$ in $P_{i}=P_{H S}=148$ Euros/t.

\begin{tabular}{|c|c|c|c|c|}
\hline Discount rate & Number of uncertainties & $q^{1}$ & $K^{2}$ & Ranking of optimal levels of $q$ and $K$ \\
\hline \multirow{4}{*}{$8 \%$} & Two Uncertainties & 12.96 & 5.99 & \multirow{4}{*}{$q_{C U}^{*}>q^{*}>q_{C}^{*}>q_{D U}^{*}$} \\
\hline & Certainty (C) & 10.90 & 5.20 & \\
\hline & Competitive effect (CU) & 14.04 & 6.39 & \\
\hline & Demand (DU) & 10.21 & 4.93 & \\
\hline \multirow{4}{*}{$12 \%$} & Two Uncertainties & 12.96 & 6.85 & \multirow{4}{*}{$q_{C U}^{*}>q^{*}>q_{C}^{*}>q_{D U}^{*}$} \\
\hline & Certainty (C) & 10.90 & 5.94 & \\
\hline & Competitive effect (CU) & 14.04 & 7.32 & \\
\hline & Demand (DU) & 10.21 & 5.63 & \\
\hline
\end{tabular}

(1) In ton per hour; (2) In MEuros. 